\title{
CONEXÕES FUNDAMENTAIS: \\ AFINIDADE E CONVERGÊNCIA NOS ESTUDOS DA \\ INTERPRETAÇÃO
}

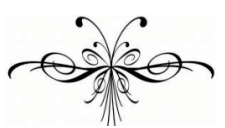

FRANZ PÖCHHACKER

\begin{abstract}
Este artigo reflete a respeito da identidade e do status da interpretação comunitária enquanto um campo de prática e de pesquisa acadêmica. Com o foco na pesquisa e no papel que esta exerce no processo de profissionalização, o artigo explora as afinidades entre os diversos campos de interpretação, de um ponto de vista histórico, conceitual e com base na dimensão social da academia. A partir de uma revisão da jovem disciplina dos "Estudos da Interpretação", em termos de diferentes paradigmas, faz-se uma análise de similaridades e inter-relações dos Estudos da Interpretação - tal como a interpretação comunitária - como parte do extenso campo dos Estudos da Tradução. A imagem que surge dessa análise exibe a abordagem dialógica interacionista - desenvolvida essencialmente para pesquisas em interpretação comunitária, um paradigma particular que oferece grande potencial para relacionar-se sinergeticamente com outras abordagens teóricas e metodológicas nos Estudos da Interpretação.
\end{abstract}




\section{Introdução}

Com o objetivo de instituir a interpretação comunitária como um campo de prática e de pesquisa no domínio dos Estudos da Interpretação, gostaria de explorar a idéia de "conexões" em várias dimensões - incluindo trajetória profissional, modelos e paradigmas. Obviamente, meu principal pressuposto é o de que a evolução da profissão implica reflexões sistemáticas e investigações acadêmicas, de tal forma que "profissão" e "pesquisa" sejam complementares ("conectadas") e que um artigo focalizado na pesquisa deva ser relevante na esfera da profissionalização.

Outro pressuposto básico é o de que a interpretação é uma forma de tradução, no seu sentido amplo, e que os Estudos da Interpretação como disciplina, mesmo que abertos a uma variedade de abordagens interdisciplinares, têm um lugar no amplo campo dos Estudos da Tradução. A afinidade entre tradução e interpretação não será tratada aqui por falta de espaço; uma ampla discussão sobre o tema pode ser encontrada no trabalho de Schäffner (2004).

Mais importante para a minha argumentação do que a relação conceitual entre 'interpretação' e 'tradução' são as distinções aplicadas ao conceito de interpretação como tal. Ao longo da maior parte da história, a interpretação era simplesmente interpretação, havendo pouca necessidade de subcategorizações. No entanto, no século XX, quando a interpretação consecutiva, com o uso de anotações, e a interpretação simultânea, feita em cabine, se destacaram, a distinção, de um modo geral, foi feita com referência ao modo temporal de sua realização, ou seja, consecutiva versus simultânea. O cenário - organizações internacionais e conferências - estava pressuposto e não era um ponto controverso Com a emergência de novos cenários e domínios profissionais a partir do fim do século XX, a tradicional distinção baseada no modo tornou-se menos efetiva; e sugiro que o critério mais relevante talvez seja a esfera social de interação onde a interpretação acontece. Em outras palavras, a interpretação seria diferenciada principalmente pelos cenários institucionais, a destacar, por exemplo, a interpretação médica, a interpretação juramentada, a interpretação midiática, ou, para reavivar um termo antigo, a interpretação parlamentar.

De maneira mais geral, venho propondo uma concepção da interpretação como um contínuo conceitual com duas grandes distinções: primeiro, entre internacional e intra-social - ou baseada em cenários comunitários -; e, segundo, com relação ao formato da interação - prototipicamente, multilateral, como acontece em conferências, versus diálogos face a face. Tomar essas duas dimensões conceituais como base permite levar em conta muitas diferenciações intermediárias, incluindo eventos similares a conferências dentro de comunidade (especialmente envolvendo surdos) ou interpretação de diálogos, em diplomacia, donde a sobreposição das duas elipses que aparecem na figura 1. 


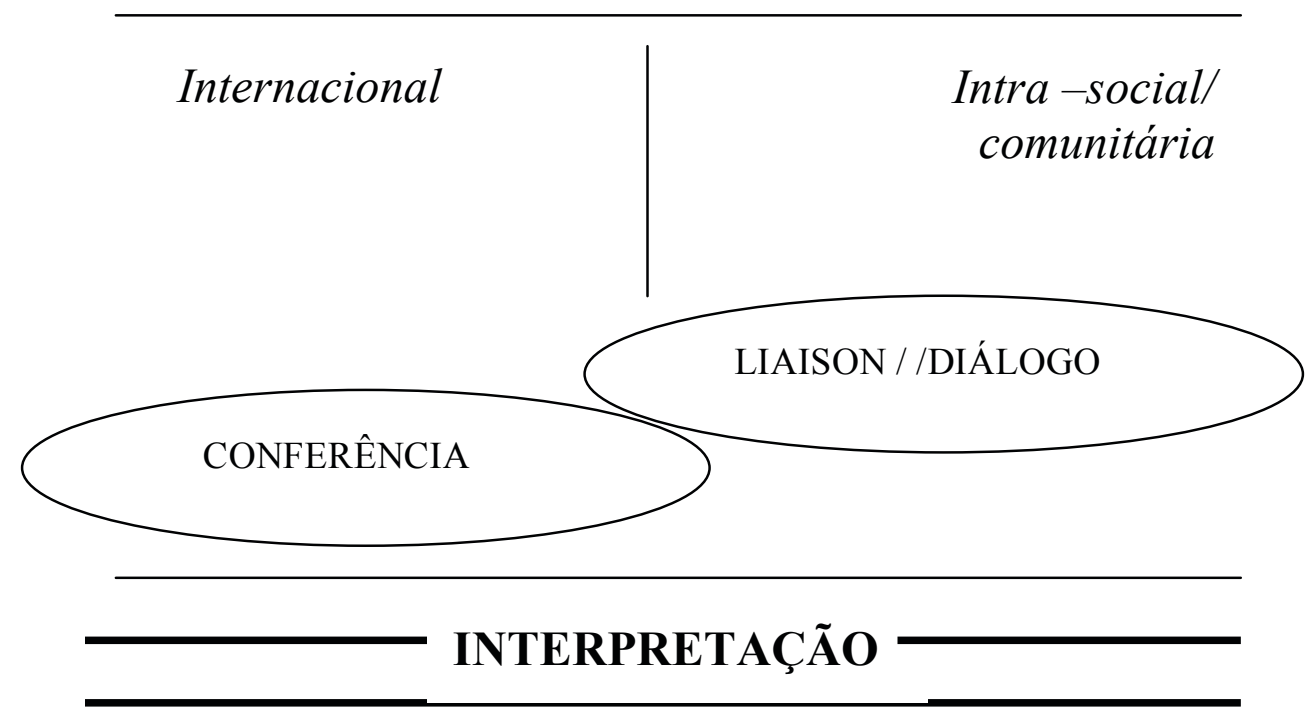

Figura 1: esboço conceitual da interpretação

Certamente, existem muitos outros critérios relevantes para caracterizar essa distinção bipolar, sendo as mais importantes os papéis dos interagentes (representante institucional versus individual) e as relações de poder. Uma distinção mais delicada é aquela entre formas de interpretação mais profissionais versus menos profissionais. Visivelmente, o que é, ou não, considerado profissional depende da especificidade da realidade social, política e econômica; e ainda que essas sejam questões vitais com as quais temos que lidar, o ponto é que o título "profissional" não está necessariamente ligado a uma área particular no espectro conceitual. Descritivamente, é claro, podemos dizer que a profissionalização, não importa como for definida, não é tão mais avançada num campo da interpretação do que num outro. Normalmente, ouvimos isso com referência à interpretação comunitária vis-àvis interpretação simultânea em conferências internacionais. Por essa razão, gostaria de citar um exemplo da história que aponta para a herança de 450 anos de intérpretes profissionais em comunidades.

\section{Trajetórias profissionais}

Um componente chave no processo de profissionalização são as disposições legais que regem o exercício de uma tarefa. Na Espanha do século XVI, tais regulamentações feitas pela autoridade suprema eram de fato aplicadas consistentemente aos intérpretes envolvidos na administração das colônias americanas da coroa espanhola. A recopilação da legislação colonial (Recompilación 1791) inclui um total de quatorze leis que regulamentavam o trabalho dos intérpretes, necessário para negociações de cunho legal e administrativo com populações indígenas. Essa legislação, nas formas de decretos de Governadores e de leis do rei da Espanha, estipulava, entre outras coisas, 
- que os intérpretes para língua(s) indígena(s) devem ter as aptidões e as qualidades necessárias, e devem ser pagos com fundos da Corte.

- que os intérpretes não devem pedir ou aceitar presentes ou brindes dos índios ou de qualquer outro povo;

- que os intérpretes não devem participar de reuniões privadas com clientes indígenas;

- que os intérpretes não devem agir como defensores dos índios;

- que os intérpretes enviados para uma missão fora do seu domicílio devem receber diárias;

Essas disposições estão relacionadas a importantes aspectos da ética profissional; mas mais impactante ainda é ler o que o governador Antonio de Mendoza, vice-rei e governador da "Nova Espanha", estipulara no começo do século dezesseis como os padrões da atividade de intérprete: Os intérpretes tinham de jurar realizar "satisfatória" e fielmente" a sua missão e expressar "clara e francamente" o assunto em questão, "sem omitir ou adicionar nada", "sem agir a favor de qualquer uma das partes" e "sem qualquer lucro além do pagamento devido a eles" (cf. Mendoza, 1548: xxxi).

Sem dúvida, tanto os intérpretes de conferências internacionais - que fundaram o seu código de ética na década de 50 quanto os intérpretes de língua de sinal nos Estados Unidos - que redigiram o seu na década de 60 - podem olhar com orgulho para esses precedentes de regulamentação em benifício dos seus clientes e da profissão. No entanto, o fato é que embora as disposições do século XVI não tenham sido desenvolvidas pelos próprios intérpretes, foram desenvolvidas expressamente para a interpretação comunitária, a qual, desse modo, ostenta profundas raízes profissionais. Embora o meu conceito de interpretação não me permita dizer que a interpretação comunitária é “o 'tipo' de interpretação mais antiga do mundo" (Roberts 1997:7) o exemplo dos antigos códigos espanhóis, embora problemático, devido ao seu contexto de poder e domínio colonial, mostra que a interpretação comunitária tem uma herança impressionante.

Durante a maior parte do século XX, evidentemente, a profissionalização da interpretação aconteceu na esfera das conferências e organizações internacionais. A interpretação de língua de sinais nos Estados Unidos e a interpretação de língua oral em contextos comunitários em países de imigração, tais como a Austrália, a Suécia e o Reino Unido, deram grandes passos nos anos 70, mas os vários domínios estavam visivelmente tomando diferentes trajetórias, praticamente sem nenhuma intersecção. A exceção mais notável foi o simpósio da OTAN em Veneza, em 1977 (Gerver \& Sinaiko 1978), o qual deu destaque tanto à interpretação de conferência internacional quanto à interpretação de língua de sinais, com pelo menos alguma alusão à interpretação liaison e a questões interacionais tais como papel e poder.

Foi apenas no decorrer dos anos 80 que intérpretes em diferentes campos começaram a tomar um maior conhecimento uns dos outros. Várias reuniões e publicações (Longley 1984; McIntire, 1984) refletem o envolvimento considerável da comunidade de intérpretes de conferência em iniciativas em prol da profissionalização e, especialmente, da formação, de intérpretes para cenários comunitários. Tal envolvimento pode parecer óbvio, e, provavelmente, o era, mas ele 
também tem limites óbvios. Métodos de treinamento voltados para habilidades tais como a feitura de anotações e a tradução oral à prima à vista, as quais são ensinadas aos aspirantes a intérpretes de conferência, poderiam ser igualmente úteis aos intérpretes comunitários, na medida em que a interpretação é vista essencialmente como uma tarefa baseada no processamento de linguagem. No entanto, quanto mais destacarmos os aspectos institucionais e comportamentais das interações mediadas, maior a probabilidade que aptidões em interpretação de conferência se mostrem insuficientes para as reais necessidades de treinamento de intérpretes comunitários. Isso levanta uma questão fundamental em nossa busca por afinidades - para ser mais preciso: até que ponto existe um terreno comum no que nós concebemos como interpretação? Existe um modelo comum que pode sustentar a(s) nossa(s) abordagem(s) tanto para o treinamento como para a pesquisa?

\section{Modelos}

Se definirmos 'modelo' como 'uma forma de ver', uma forma de representar um fenômeno através da identificação de seus componentes e das relações entre eles, parece realmente haver um consenso de que o modelo de interpretação constitui-se de três partes - como estrutura tripartite e muitas vezes de estrutura triangular. Isso poderia sugerir um nível de concordância impressionante. No entanto, existe uma diferença fundamental a respeito da natureza desses três componentes. Isso é o resultado de duas formas diferentes de se pensar a interpretação: como um processo mental ou como um processo de interação social. No primeiro caso, o triângulo reflete as principais fases do processo cognitivo; no segundo, representa as três partes principais envolvidas na interação. Tendo as etapas do processo e os papéis das interações como os seus respectivos pontos focais nós podemos, então, falar da dualidade dos modelos tripartites: modelos de processamento, por um lado, e modelos de interação, por outro. O exemplo mais famoso de um modelo de processamento triangular de interpretação é sem duvida o modelo de Seleskovitch, desenvolvido posteriormente por autores como García-Landa (1981) e Laplace (1994); uma versão original do modelo de interação tripartite é provavelmente o modelo de caso e tipo de constelação tripartite de Anderson (1976), uma elaboração particularmente detalhada do que é oferecido por Bélanger (2003).

Essas diferentes formas de observar e modelar o fenômeno avançam, de alguma forma, na direção de explicar a existência de mais do que uma única tradição de pesquisa nos Estudos da Interpretação. Todavia, um modelo compartilhado é apenas parte do terreno comum necessário a uma comunidade de pesquisadores. Um conjunto de suposições, valores e métodos-padrão básicos também precisa ser compartilhado por membros de uma comunidade científica para que haja o que Thomas Kuhn (1962) definiu como "paradigma" - uma "visão de mundo" que molda a maneira do pesquisador "fazer ciência". No próximo tópico, eu gostaria de usar a noção de paradigma para, brevemente, apresentar um esboço de cinco décadas de pesquisas em interpretação, com o objetivo de mostrar o surgimento e a convergência das várias vertentes. 


\section{Paradigmas}

Com algumas poucas e interessantes exceções, as pesquisas em interpretação se iniciaram nos anos 60, quando psicólogos interessaram-se pela habilidade espetacular da interpretação simultânea. Empregando o(s) seu(s) próprio(s) paradigma(s), eles estudaram a interpretação - por meio de experimentos - como uma forma de processamento de linguagem em vez de como um serviço profissional. Este segundo aspecto era mais proeminente nos artigos de intérpretes de conferência, Danica Seleskovitch a principal deles. Já em 1962, Seleskovitch publicou um artigo no qual descreveu a interpretação de conferência enquanto atividade profissional e ofereceu, também, uma explicação provisória do processo cognitivo subjacente: seu famoso modelo de três fases, que se baseia no "sentido" independente da língua (Seleskovitch 1962: 16). Por volta da mesma época, Otto Kade (1963), na então Alemanha Oriental, publicou um artigo sobre a tomada de notas em interpretação consecutiva, em que levantou a hipótese da existência de seis estágios de processamento, incluindo o dos conteúdos conceituais. Tanto Kade quanto Seleskovitch publicaram importantes monografias em 1968 e, no entanto, não ocorreram "conexões" entres esses pioneiros da França e da Alemanha oriental Pelo contrário, a associação de Kade com a chamada Escola Tradutológica de Leipzig, que situou o estudo da tradução e da interpretação no âmbito da lingüística, e procurou por relações de equivalência entre os sistemas lingüísticos, mostrou-se tão fragmentador quanto a barreira física da Cortina de Ferro. Para Seleskovitch, regras de transferência lingüística - tais como implementadas à época para a tradução automática - eram diametralmente opostas à sua idéia de interpretação como um processo de produção de sentido com base no conhecimento de mundo do intérprete e do contexto situacional da interação.

Foi esse foco no contexto de interação autêntico que fez de Seleskovitch igualmente cética quanto a experimentos psicológicos sobre a interpretação realizada em laboratório, como tipificada naquele momento pela pesquisa pioneira de doutorado de Henri Barik (1969). Embora seja verdade que o estudo de Barik sofresse de graves problemas quanto ao desenho do experimento, o trabalho do também psicólogo David Gerver (1971) demonstrou claramente que seria possível obter insights úteis para a prática de interpretação profissional a partir de experimentos controlados. Em sua tese de doutorado de 1971, Gerver definiu interpretação como "uma forma bastante complexa de processamento de informação humana, envolvendo recepção, armazenamento, transformação e transmissão da informação verbal" (Gerver 1971: viii). Essa idéia de interpretação como uma habilidade complexa de processamento de informação encontrou um ambiente muito favorável nos anos 70, quando a interdisciplinaridade das ciências cognitivas emergiu como um novo e promissor paradigma de ordem superior para o estudo do processamento da linguagem e de outras funções cognitivas. No entanto, durante esse período, o estudo da interpretação permaneceu nas mãos dos intérpretes de conferência profissionais, liderados por Seleskovitch, quem conseguiu fundar programa de doutorado na Universidade de Paris, em 1974. Nesse contexto, um paradigma único floresceu baseado na teoria interpretativa de Seleskovitch (TI) e na observação do desempenho profissional real em vez de na de experimentos 
laboratoriais. O paradigma da teoria interpretativa da chamada Escola de Paris funcionou como previsto para um paradigma: por mais de uma década foi a abordagem teórica e metodológica dominante no estudo - e ensino - de interpretação de conferência.

No inicio dos anos 80, no entanto, um grupo de intérpretes de conferência, incluindo Daniel Gile, Jennifer Mackintosh, Barbara Moser-Mercer e Catherine Stenzl, demandou uma abordagem de investigação mais (auto-) crítica e científica. O Simpósio de 1986 na Universidade de Trieste (Gran \& Dodds 1989) tornou-se um evento histórico onde essa "nova geração" questionou abertamente as certezas da Escola de Paris e clamou pelo renascimento da investigação empírica, e muitas vezes experimental, em cooperação com outras disciplinas. Com foco na interpretação como um processamento cognitivo (PC), na tradição de Gerver, o paradigma PC se mostrou aberto às abordagens interdisciplinares vindas dos amplos domínios da psicologia e, em menor proporção, da lingüística. Mais especificamente, a neuropsicologia cognitiva serviu como um modelo analítico para estudar a lateralização das funções lingüísticas no cérebro, dando origem a um paradigma neurolinguístico (NL) de pesquisa em interpretação (por exemplo, Fabbro et al. 1990).

Por outro lado, a concepção da linguística de texto orientada pelo processo, como desenvolvida por Robert de Beaugrande (1980) em particular, com base nos avanços da ciência cognitiva, ajudou a direcionar a atenção para o produto textual do intérprete. A idéia de interpretação como produção de texto foi compartilhada por um grupo de pesquisadores em tradução que, no curso dos anos 80, (re-) conceitualizou tradução (e interpretação) como uma 'atividade dotada de propósitos', cuja finalidade não é a 'reprodução equivalente' do texto fonte, mas a produção do texto alvo designado a atender a sua função no contexto da cultura alvo. A tradução, desse ponto de vista, não era uma transferência linguística, mas um processo que abarca dois sistemas culturais, o qual exige a mediação ativa de sentido para atender as necessidades culturais do contexto alvo. Liderada por Hans Vermeer na Universidade de Heidelberg, a teoria da tradução funcionalista alemã, ou teoria do escopo, mostrou-se amplamente compatível com a abordagem ao estudo de tradução decididamente descritiva, orientada ao alvo, como promovida por Gideon Toury (1995), em particular. Embora nenhuma das duas versões de abordagem teórica da tradução orientada pelo texto alvo (OA), tenham ganhado grande visibilidade nas pesquisas em interpretação, os estudos que têm sido realizados na área (como por exemplo, Shlesinger 1989, Pöchhacker, 1994) são distintos o bastante para justificar a identificação de um tal paradigma de pesquisa em interpretação.

Esse esboço da evolução dos paradigmas de investigação em interpretação - TI, PC, NL, OA nos leva até meados dos anos 80. Ainda assim, se olhada da perspectiva das conexões fundamentais, tudo isso poderia ser posto de lado como "pré-histórico", como predecessor do surgimento pleno da interpretação comunitária no cenário internacional, na primeira conferência "Critical Link" em 1995 (Carr et al. 1997). Em tal ocasião, abordagens inovadoras aos Estudos da Interpretação como interação foram consolidadas no seio de uma comunidade emergente de pesquisadores. De maior conseqüência, a perspectiva da interpretação de Cecília Wadensjö como sendo um discurso administrado numa relação triádica, onde o foco recai mais na 
interatividade do que na produção monológica de um texto, deu forma a um novo paradigma. Centrado no discurso e interação dialógicos (DI), esse paradigma inspirou-se, sobretudo, nos conceitos e métodos de áreas tais como a sociolingüística, a análise de conversação e a psicologia social. Como evidenciado por importantes contribuições de pesquisadores em interpretação de língua de sinais, tal como Cynthia Roy (2000), o paradigma DI provou servir bem tanto para a interpretação da língua falada como para a língua de sinais. De fato, um dos pontos fortes da comunidade de pesquisadores envolvida na organização das conferências "Critical Link" é conectar os interesses dos intérpretes comunitários nas duas modalidades.

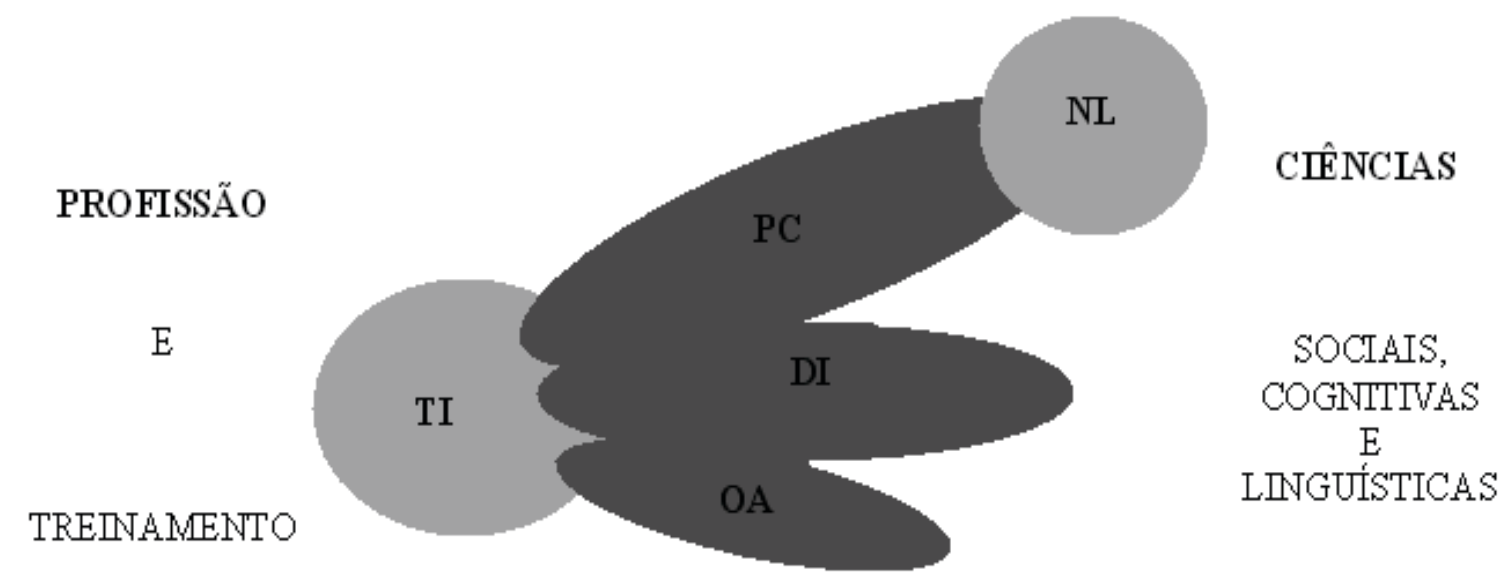

Figura 2: Agrupamento de paradigmas em Estudos da Interpretação.

Embora não haja espaço neste trabalho para uma discussão mais detalhada (ver Pochhacher 2004), a figura 2 oferece uma visualização intuitiva a fim de caracterizar a posição dos vários paradigmas no espaço disciplinar que se estendem da esfera da prática e treinamento profissionais, por um lado, até as disciplinas científicas já estabelecidas, por outro. O paradigma TI original aparece principalmente no domínio da prática e treinamento profissionais. Dele decorre o paradigma PC, com mais aspirações científicas, tendo-se o paradigma NL como seu desenvolvimento mais especializado. O paradigma OA está representado na base, com certa autonomia em relação às disciplinas cientificas já estabelecidas. O mais importante para o propósito desta discussão é o paradigma DI, que aparece como um conector, tanto entre as esferas profissionais quanto entre os paradigmas PC e OA da disciplina. Como indicam os dois lados da sua forma elíptica, o paradigma DI é nutrido por ambos: prática profissional e disciplinas científicas, e conta com representantes oriundos da profissão, como Holly Mikkelson, e outros, como Ian Mason, que trabalham a partir de uma base disciplinar das ciências relacionadas com a linguagem. 
O mapa dos paradigmas ilustrado na figura 2 sugere importantes sobreposições e eu gostaria de discutir com mais detalhes o que poderiam ser essas áreas de convergência nos Estudos da Interpretação.

\section{Convergência?}

Além de algum terreno comum básico nos campos conceitual e metodológico, há muitas áreas de interesse compartilhadas por muitos pesquisadores da interpretação que transpassam diferentes setores e paradigmas. Vou me concentrar em algumas amplas áreas de interface, no que diz respeito aos cenários, aos modos de atuação e aos tópicos.

Entre os cenários onde a interpretação ocorre, os tribunais ocupam uma posição central de várias maneiras. Enquanto a formalidade nos procedimentos e o uso de terminologia especializada fazem dos procedimentos de interpretação em tribunais similares àqueles que ocorrem em conferências, o envolvimento do réu que participa da interação como seu próprio representante (legal), normalmente um falante de uma língua minoritária, é uma característica definidora da interpretação sob bases comunitárias. Além disso, o uso de tradução simultânea, no modo "sussurrando", é comum (pelo menos em algumas jurisdições), tornando, assim, as bases das competências do intérprete de tribunais comparável àquelas do intérprete de conferências.

Um ponto similar de interface entre os cenários de interpretação são as mídias - e a literatura recente ilustra muito bem o fato de que esse território é compartilhado por intérpretes que trabalham com interpretação simultânea em conferências, intérpretes de língua de sinais e, do mesmo modo, intérpretes de diálogos, em linguagem oral. Ainda mais óbvio do que isso, as negociações bilaterais nos setores da diplomacia e do comércio desde há muito são consideradas como o território profissional de intérpretes com formação de alto nível em interpretação de conferências, ainda que tais negociações normalmente impliquem a ocorrência do formato de interpretação de diálogo face a face, presumidamente com uma boa porção de organização e mediação do discurso. Existem alguns relatos anedóticos fascinantes, mas muito pouca pesquisa, uma vez que esse tipo de situação é altamente delicado e, portanto, muito 'confusa' de estudar nesse campo. Aqui, estudos de caso sobre interpretação de diálogo em cenários comunitários não menos delicados poderiam servir de modelo para os pesquisadores interessados em interpretação de diálogo na esfera internacional.

Outra área central de interface para a pesquisa é o modo simultâneo, o qual tem sido predominante na literatura por décadas. $O$ fato de que os intérpretes de língua de sinais formalmente instruídos trabalham, tipicamente, ainda que não exclusivamente, no modo simultâneo, e que os intérpretes comunitários de língua oral também usam esse modo, como, por exemplo, em testemunhos de peritos em tribunais, ou em prescrições terapêuticos, fazem do modo simultâneo uma questão compartilhada significante em vez de - como algumas vezes se alega - uma característica distintiva que coloca a interpretação de conferência internacional à parte.

Scientia Traductionis, $n .7,2010$ 
Finalmente, no que diz respeito aos tópicos, eu gostaria de expor três temas sobre os quais investigadores de diferentes domínios podem convergir.

O primeiro, o papel dos "fatores psicossociais", foi salientado por ninguém menos do que David Gerver, que a partir de sua definição de interpretação como uma forma complexa de processamento de informação humana (mencionada anteriormente) declarou o seguinte: "Ademais, entre muitos outros fatores, os fatores lingüísticos, motivacionais e situacionais não podem ser ignorados." Gerver, 1976:167) Falar de "muitos outros fatores" oferece, claramente, uma extensa margem de manobra, mas mesmo somente os aspectos "motivacional" e "situacional" deveriam ser suficientes para promover uma defesa forte de uma orientação sociolingüística, no senso mais amplo, a qual enfatize os objetivos e intenções, experiência e relacionamentos, das partes interagentes. Isso é altamente compatível com o apelo de Cecília Wadensjö "por uma virada micro-sociológica nos Estudos da Interpretação" ([1993]/2002:368) e não é menos apropriado às abordagens teóricas de tradução orientadas pela função e pela norma.

Outro tema de convergência é o "discurso", que está intimamente associado com uma orientação sociolingüística (amplamente construída). Historicamente, pode-se mostrar que o trabalho de Gumperz e Hymes (1972), por exemplo, informa muito sobre as ponderações de Vermeer a respeito das interações mediadas entre diferentes culturas, além de, é claro, ser central para o paradigma DI. O trabalho de Hatim e Mason (1990) estabeleceu com sucesso o rico campo do discurso para os Estudos da Tradução e Interpretação, reafirmando abordagens tais como a lingüística de texto de Beaugrande e Dressler (1981) e a gramática do discurso de Hallidayan (1978) como bases valiosas.

Desde os anos 70, a noção de discurso, e da análise do discurso, tem se expandido em proporções de assombrosas tal modo que, hoje em dia, esta é uma noção amplamente abrangente e sinônima de estudo da linguagem e da comunicação (e muito mais). O fato de que o discurso, tal como estudado agora, pode significar qualquer coisa, desde a designação de uma referência anafórica até a análise de discursos racistas, pode fazer essa noção parecer um tanto desordenada; por outro lado, é um denominador comum bem-vindo para o estudo do "processo cognitivo do discurso" e da "gestão de discurso em interação", e pode, efetivamente, servir para atenuar a distinção entre os dois.

Isso é precisamente o que está no coração do terceiro tema de convergência, o qual poderíamos chamar de "cognição em comunicação". Robin Setton (1999) é o principal representante dessa abordagem no estudo da interpretação, o qual se inspira principalmente na lingüística cognitiva, na teoria dos atos de fala e na teoria da relevância,. A "análise cognitiva-pragmática" de Setton complementa princípios básicos do paradigma TI com uma aplicação rigorosa de estruturas conceituais da linguística na ciência cognitiva; mas seu trabalho também é congenial com o paradigma DI. Até agora, as análises empíricas feitas por Setton foram baseadas em transcrições de discurso monológico de conferências e interpretações simultâneas, mas o seu quadro conceitual parece bem adaptado também ao discurso dialógico. Em vez de quantificar características textuais, o interesse de Setton reside numa microanálise qualitativa - feita segundo a segundo - do processo do discurso comunicativo, ancorada na representação mental dirigida pelo conhecimento assim como por 
inputs. A interface com a "análise micro-sociológica" do discurso de Wadensjö é bastante evidente, de modo que três temas de convergência na teoria da interpretação que estou sugerindo aqui estão estreitamente relacionados.

Em consonância com a tradição de modelagem triangular, podem-se descrever as três áreas de convergência numa estrutura tripartite (Fig. 3).

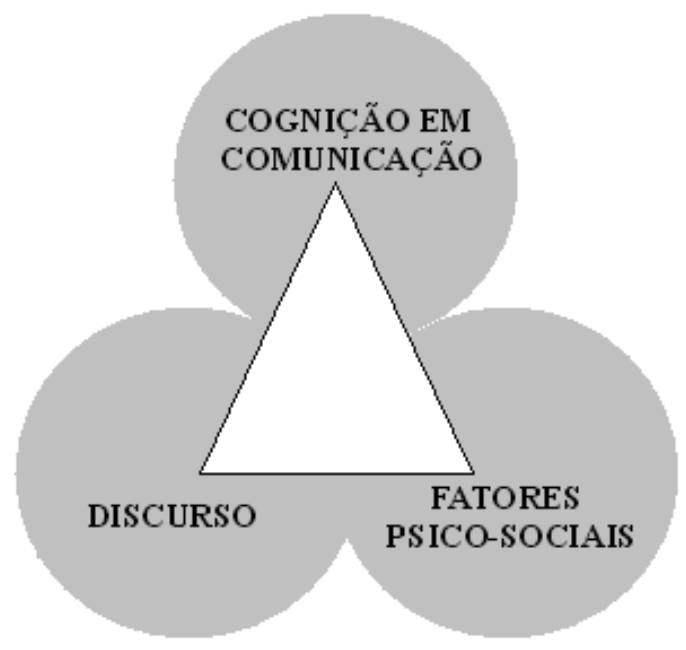

Figura 3: Temas de convergência.

Esses temas, sugiro, provavelmente irão conduzir a uma convergência na teoria da interpretação que transpasse os vários paradigmas da disciplina - se, para início de conversa, aceitarmos a noção de diferentes paradigmas. Afinal, no relato original de Kuhn (1962) os paradigmas foram concebidos como mutuamente incompatíveis. Considerando a crescente aceitação das múltiplas perspectivas e do pluralismo metodológico em nosso campo, parece razoável esperar por um ofuscamento dos contornos entre os paradigmas, e, assim, por um espaço disciplinar cada vez mais coerente.

\section{Conclusão}

Para concluir, espero ter mostrado que existem muitas manifestações de afinidades nos Estudos da Interpretação e que dividir o campo em paradigmas separados puramente com base em domínios profissionais não seria proveitoso para a pesquisa em interpretação como um todo, já que isso poderia obscurecer produtivas conexões e inter-relações. O que eu chamei de paradigma DI, centrado na análise dos discursos em interação, tem grande potencial como esfera de convergência das várias abordagens teóricas e metodológicas, e pode de fato desempenhar um papel fundamental na evolução dos Estudos da Interpretação como disciplina. 


\section{References}

ANDERSON, R. B. W. 1976. "Perspectives on the role of interpreter." In Translation: Applications and Research, R. W. Brislin (ed.), 208-228. New York: Gardner Press.

BARIK, H. C. 1969. A Study of Simultaneous Interpretation, doctoral dissertation, University of North Carolina, Chapel Hill.

BEAUGRANDE, R. de. 1980. Text, Discourse and Process. London: Longman.

BEAUGRANDE, R.-A. de and Dressler, W. U. 1981. Introduction to Text Linguistics, London: Longman.

BÉLANGER, D.-C. 2003. "Les différentes figures d'interaction en interprétation de dialogue." In The Critical Link 3: Interpreters in the Community, L. BRUNETTE, G. BASTIN, I. HEMLIN and H. CLARKE (eds), 51-66. Amsterdam/Philadelphia: John Benjamins.

CARR, S. E., ROBERTS, R., DUFOUR, A. and STEYN, D. (eds). 1997. The Critical Link: Interpreters in the Community. Papers from the First International Conference on Interpreting in Legal, Health, and Social Service Settings (Geneva Park, Canada, June 1-4, 1995). Amsterdam/Philadelphia: John Benjamins.

FABBRO, F., GRAN, L., BASSO G. and BAVA A. 1990. "Cerebral lateralization in simultaneous interpretation." Brain and Language 39: 69-89.

GARCÍA-LANDA, M. 1981. “La 'théorie du sens', théorie de la traduction et base de son enseignement." In L'enseignement de l'interprétation et de la traduction: de la théorie à la pédagogie, J. DELISLE (ed.), 113-132. Ottawa: University of Ottawa Press.

GERVER, D. 1971. Aspects of Simultaneous Interpretation and Human Information Processing, D. Phil. thesis, Oxford University.

GERVER, D. 1976. "Empirical studies of simultaneous interpretation: A review and a model." In Translation: Applications and Research, R. W. BRISLIN (ed.), 165-207. New York: Gardner Press.

GERVER, D. and SINAIKO, H. W. (eds). 1978. Language Interpretation and Communication. Proceedings of the NATO Symposium, Venice, Italy, September 26-October 1, 1977. New York/London: Plenum Press.

GRAN, L. and DODDS, J. (eds). 1989. The Theoretical and Practical Aspects of Teaching Conference Interpretation. Udine: Campanotto. 
GUMPERZ, J. J. and HYMES, D. 1972. Directions in Sociolinguistics. New York: Holt, Rinehart and Winston.

HALLIDAY, M. A. K. 1978. Language as Social Semiotic. London: Edward Arnold.

HATIM, B. and Mason, I. 1990. Discourse and the Translator. London: Longman.

KADE, O. 1963. "Der Dolmetschvorgang und die Notation." Fremdsprachen 7 (1): $12-20$.

KUHN, T. S. 1962. The Structure of Scientific Revolutions. Chicago: The University of Chicago Press.

LAPLACE, C. 1994. Théorie du langage et théorie de la traduction. Les concepts-clefs de trois auteurs: Kade (Leiprig), Coseriu (Tübingen), Seleskovitch (Paris). Paris: Didier Érudition.

LONGLEY, P. 1984. "What is a community interpreter?" The Incorporated Linguist 23 (3): 178-181.

McINTIRE, M. L. (ed.). 1984. New Dialogues in Interpreter Education. Proceedings of the Fourth National Conference of Interpreter Trainers Convention. Silver Spring, MD: RID Publications.

MENDOZA, A. de. 1548. Ordenanzas y copilación de leyes. Mexico: Juan Pablos.

PÖCHHACKER, F. 1994. Simultandolmetschen als komplexes Handeln. Tübingen: Gunter Narr.

PÖCHHACKER, F. 2004. Introducing Interpreting Studies. London/New York: Routledge.

RECOPILACIÓN. 1791. Recopilación de Leyes de los Reynos de las Indias (...), Tomo Primero. Quarta Impresión. Madrid: Viuda de Joaquín Ibarra.

ROBERTS, R. P. 1997. "Community interpreting today and tomorrow." In The Critical Link: Interpreters in the Community, S. E. Carr, R. Roberts, A. Dufour and D. Steyn (eds), 7-26. Amsterdam/Philadelphia: John Benjamins.

ROY, C. B. 2000. Interpreting as a Discourse Process. Oxford: Oxford University Press. Schäffner, C. (ed.). 2004. Translation Research and Interpreting Research: Traditions, Gaps and Synergies. Clevedon: Multilingual Matters.

SELESKOVITCH, D. 1962. “L'interprétation de conférence.” Babel 8 (1): 13-18.

SETTOON, R. 1999. Simultaneous Interpretation: A Cognitive-Pragmatic Analysis. Amsterdam/ Philadelphia: John Benjamins. 
SETTON, R. SHLESINGER, M. 1989. Simultaneous Interpretation as a Factor in Effecting Shifts in the Position of Texts on the Oral-Literate Continuum, MA thesis, Tel Aviv University.

TOURY, G. 1995. Descriptive Translation Studies and Beyond. Amsterdam/Philadelphia: John Benjamins.

WADENSJÖ, C. [1993]/2002. "The double role of a dialogue interpreter." In The Interpreting Studies Reader, F. PÖCHHACKER and M. SHLESINGER (eds), 355-370. London/New York: Routledge. 22.

WADENSJÖ, C. 1998. Interpreting as Interaction. London/New York: Longman. 
Este texto de Franz PÖCHHACKER é um dos 27 artigos selecionados em 2004, durante a conferência "Critical Link" em Estocolmo, para compor o número 4 da coleção The Critical Link da editora J. Benjamins, intitulado "Profissionalization of interpreting in the community".

A evolução da interpretação comunitária como um campo de prática e pesquisa foi foco deste e dos números precedentes dessa coleção. Tal evolução tem sido atribuída a novas necessidades sociais criadas pela ampliação do fluxo de imigrantes em países em desenvolvimento e pelo aumento do reconhecimento dos direitos de povos falantes de línguas minoritárias. O papel do intérprete comunitário, como proposto por grande parte da literatura disponível sobre o tema, é fazer a mediação linguística e cultural, garantindo assim o acesso integral dos não-falantes da língua oficial de um país aos serviços públicos, tais como os de saúde, jurídicos, educacionais, etc. Intérprete de serviço público, intérprete cultural, intérprete de liasion são outras definições que podem ser observadas.

No Brasil, ainda que haja uma clara demanda por esse tipo de serviço, pouco foi dito sobre a interpretação comunitária. Até o momento, podemos observar que o foco, tanto na esfera das pesquisas quanto na esfera da prática em interpretação ainda está massivamente focalizado na interpretação simultânea para conferências - e mesmo aí parece ainda haver muitos pontos a serem conectados entre pesquisa e prática.

Neste sentido, o texto de Pochhacker abre um campo para reflexões que podem auxiliar a identificar possíveis afinidades e conexões no aparato metodológico e teórico das pesquisas em Estudos da Interpretação, e dos Estudos da Tradução como um todo.

Fonte: Pöchhacker, F. "Critical Linking up: Kinship and Convergence in interpreting studies", in WADENSJÖ, C. The Critical Link 4: profissionalisation of interpreting in the comunnity: selected papers from the 4thInternational Conference on Interpreting in Legal, Health and Social Services Settings. Stockholm, Sweden: Jonh Benjamins, 2004. With kind permission by John Benjamins Publishing Company, Amsterdam/Philadelphia.

\author{
Mylene Queiroz. \\ Universidade Federal de Santa Catarina \\ myleneq@gmail.com
}

